\title{
خصائص اللغة الغربية وفنون تطبيقها
}

\author{
جيفرين حلاوى \\ جامعة السلطان الشريف قاسم الإسلامية الحكومية رياو، اندونيسيا \\ djeprinhulawa@gmail.com
}

\section{ملخّص}

الهدف الأساسي لتدريس اللغة العربية هو إكساب المتعلّم القدرة على الاتصال اللغوي الواضح

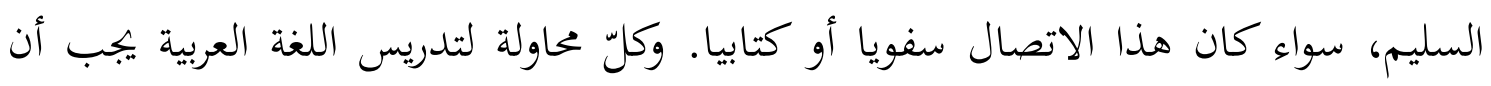
تؤدي إلى تحقيق هذا الهدف. والاتصال اللغوي لا يتعدى أن يكون بين متكلم ومستمع، أو بين كاتب وقارئ. وعلى هذا الأساس فإنّ للغة فنونا أربعة هي: الاستماع، والكالام، والقراءة، والكتابة. وهذه الفنون الأربعة هي أركان الاتصال اللعوي وهي متّصلة ببغضها تمام الاتصال وكلّ منها يؤثر ويتأثر بالفنون الأخرى. فالمستمع الجيد هو بالضرورة متحدّث جيد وقارئ جيد الميد وكاتب جيد. والقارئ الجيد، هو بالضرورة متحدّث جيد وكاتب جيد. والقارئ الجيد هو بالضرورة متحدث جيد وكاتب جيد. والكاتب الجيد لا بدّ أن يكون مستمعا جيدا وقارئا جيدا، وهذا.

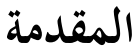

اللغة هي إحدى مخلوقات الله كما قيل في آيته الكريم: "ومن آيته خلق السماوات والأرض واختلاف ألسنتكم إن في ذلك لآية للعالمين" (الروم:YY). واللغة من أهمّ النظم الحضارية التي تجعل الانسان انسانا. للذلك، فهي تستحقّ الاهتمام الشديد لأثّا إحدى أهمّ مقاومات بناء الإنسان وبناء الأمّة كما أها إحدى أهمّ الوسائل التي تمكن الإنسان من عماراة

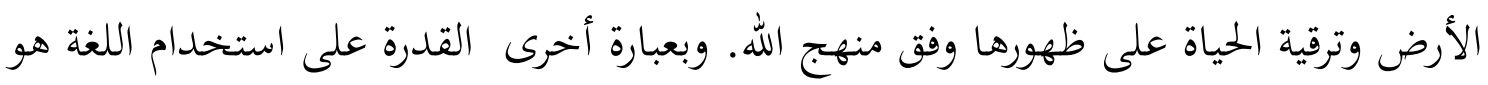
أساس النجاح الإنساني. 


\section{مفهوم اللغة وخصائصها}

ا ـ ـ تعريف كلمة اللغة

اللغة مشتقة من لغا يلعو: إذا تكلم؛ فمعناها الكلام.' أما في الاصطلاح فعرفت

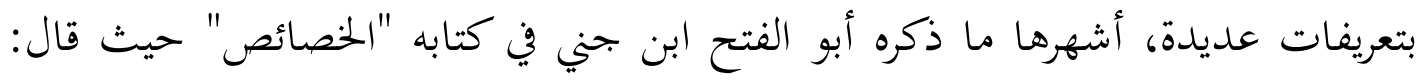

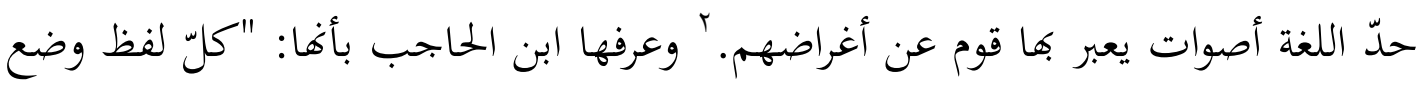

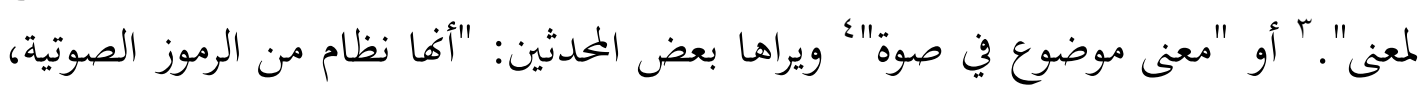

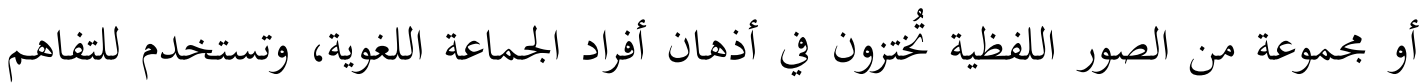

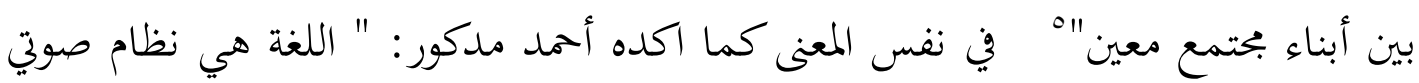
رمزي، ذو مضامين محدّدة، تتفق عليه جماعة معينة، ويستخدمه أفرادها في التفكير والتعبير المعاء

$$
\text { والاتصال فيما بينهم. }
$$

\section{أ. خصائصها}

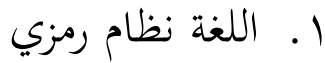

لكلّ لغة من اللعات لها نظلم خاصّ بها. وهذا النظام يتكون من الوحدات

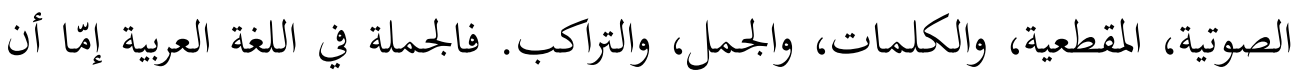

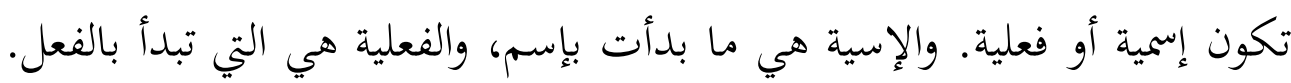

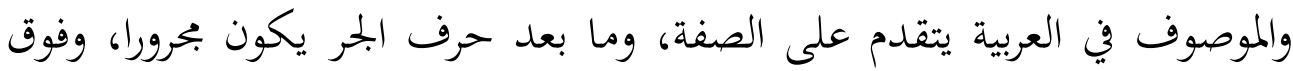

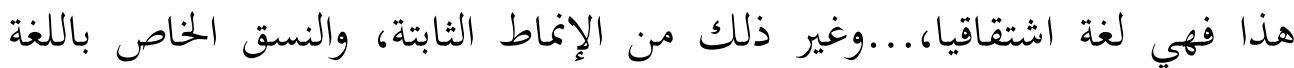

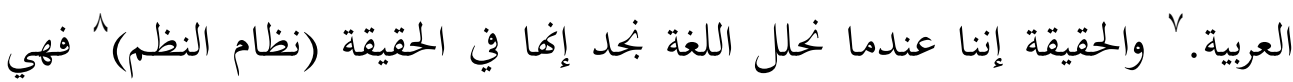

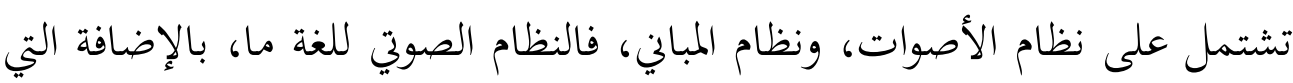

\footnotetext{
لسان العرب...101 10.101

r الخصائص rv/1

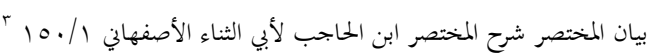

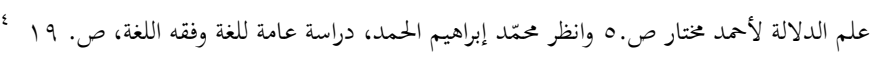

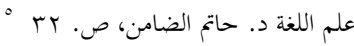

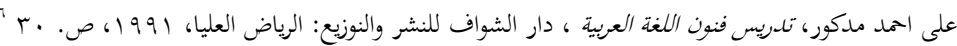

علي احمد مدكور، نفس المكان

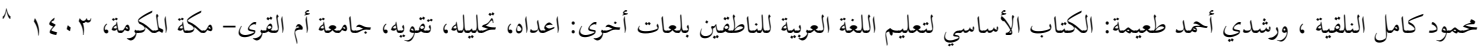
. T)
} 
نظام البنية أو التركيب، يؤديان إلى نظام المعني لهذه اللغة. فالأصوات اللغوية هي

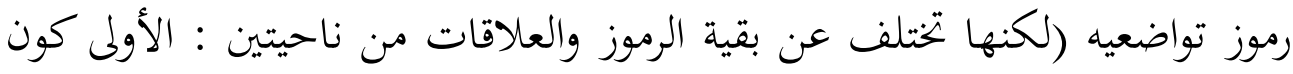

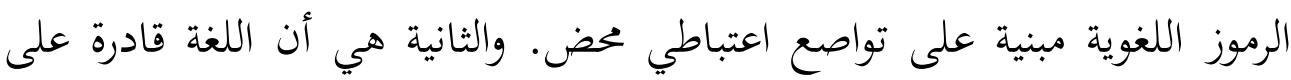
وصل رموزها بكافة خبرات الإنسان وتصوراته، وجميع أجزاء الكون ومحتوياته.

\section{T ا ب اللغة ذات طبيعة صوتية}

ومعنى كون اللعة صوتية، أن الطبيعة الصوتية فيها هي الاساس، بينما

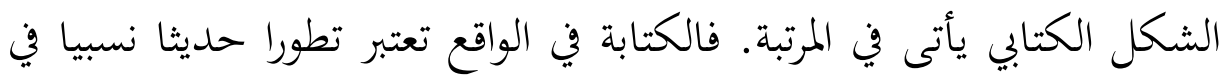

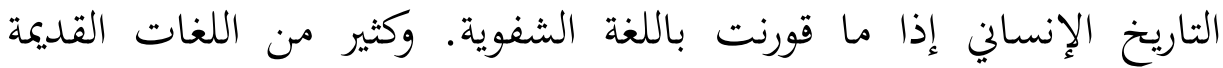

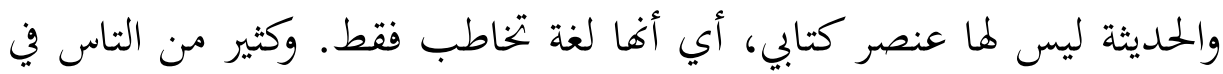
بجتمعنا اليوم يعيشون عيشة رغدة غنية دون أن يكونوا قادرين القراءة والكتابة. وفي أي حال، فإن الطبيعة الصوتية للغة تعني أن يبدأ نعليم اللغة للأطفال

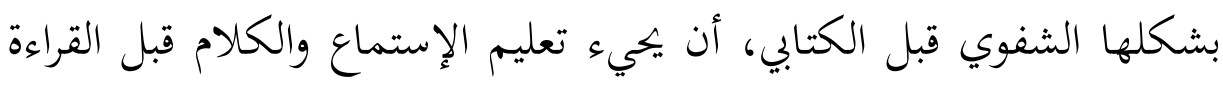

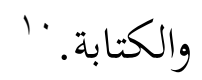

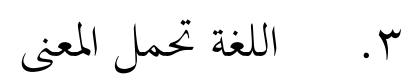

كما ذكر في السابق أن معنى اللغة متفقّ عليها بين المجتنع الذي يتكلم

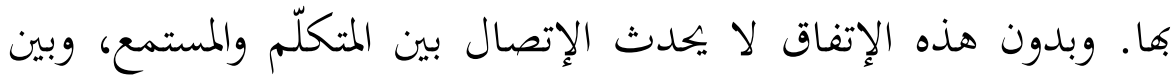

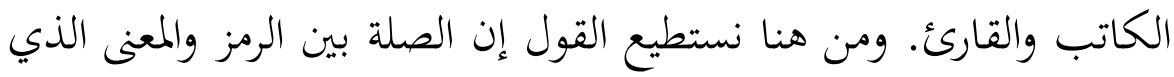

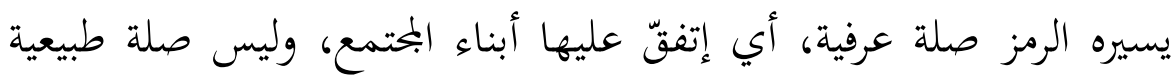

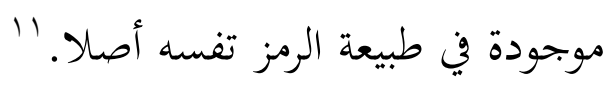

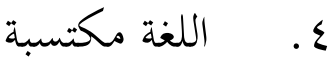

معنها أن اللغة ليست غريزة في الإنسان وكلّ إنسان لا يولد عالما بلغة

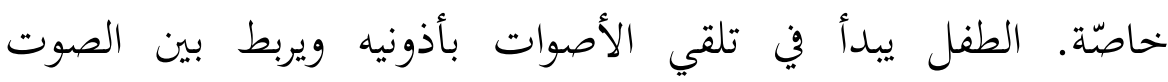

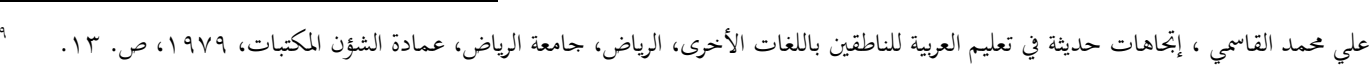

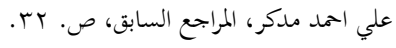

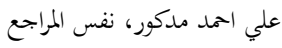


والشخص، وبين الصوت والشيء، وبين الصوت والحركة، ويدرك العلاقة

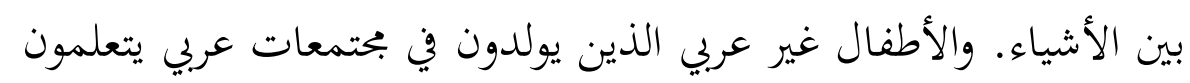

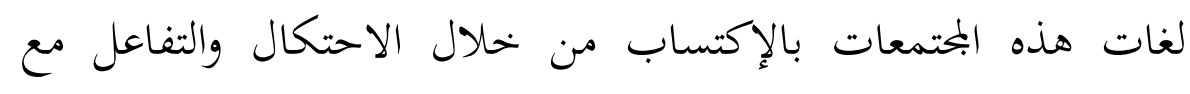
الأخرين ه. - م. اللغة نامية

معنى النمو في اللغة هي أن اللغة ليست شيئا جامد ومثبت وإنّما هي

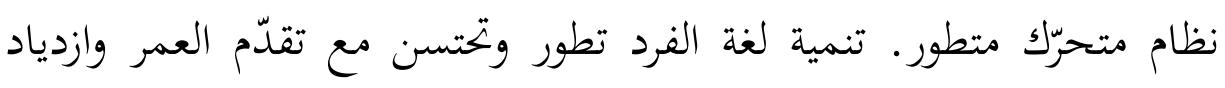

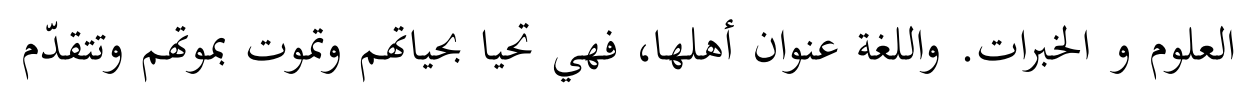

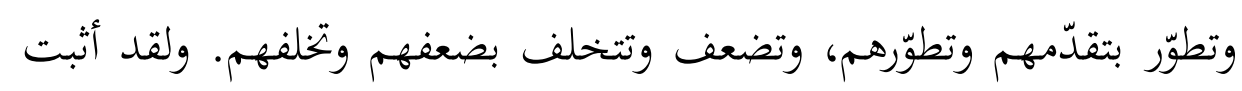

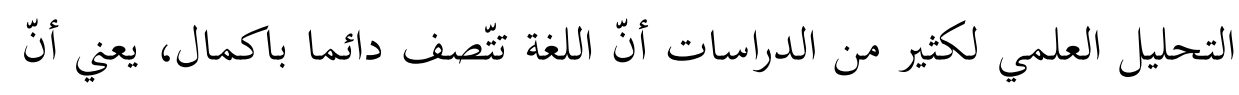

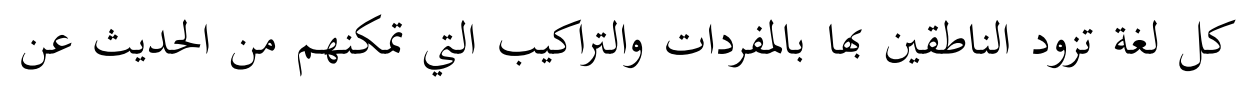

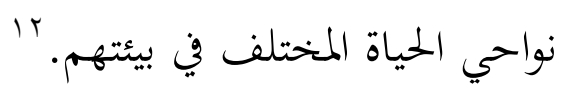

\section{7. - الغة اجتماعية}

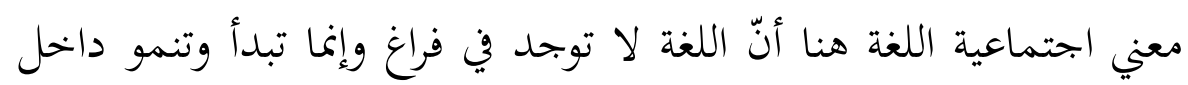

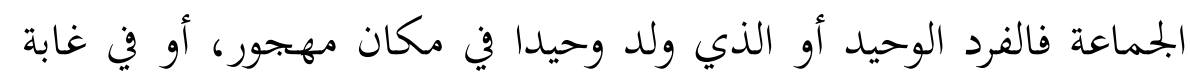

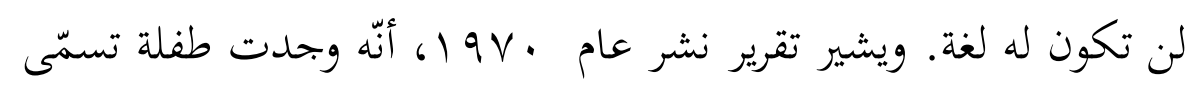

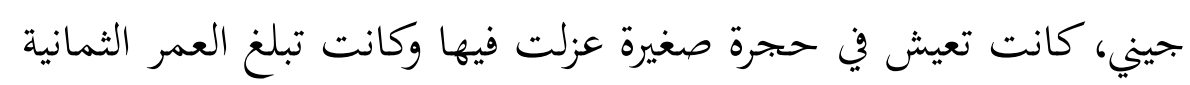

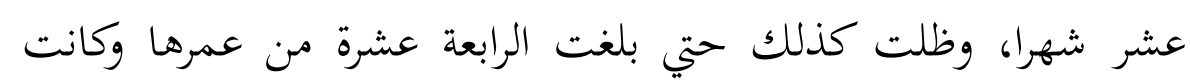

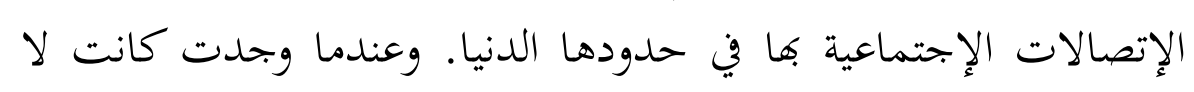
تعرف أية لغة على الإطلاق: وبدأت في تعلم اللغة مع الإنماعل الإحتكل

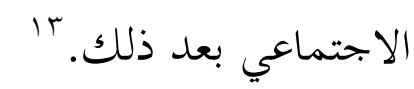

\footnotetext{
المراجع السابق، ص. rre

"r Fromkin, V. \& Roman, R., An Introduction to Language, New York, Holt, and Winston, $19 \vee \varepsilon$, p. r Iفي علي أحمد مدكور، (المراجع السابق، ص. \&ب)
} 


\section{ب. وظائف اللغة}

تنقسم وظائف اللغة بشكل عام إلى قسمين أساسيين: ؛ القفة

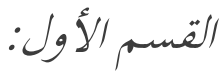

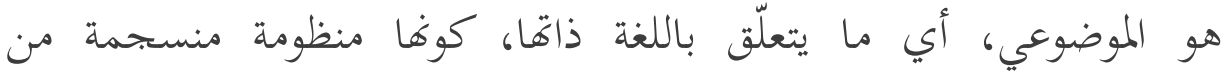

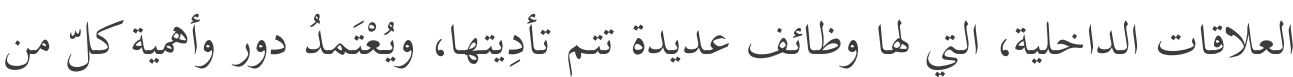

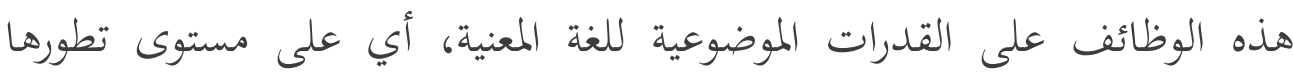

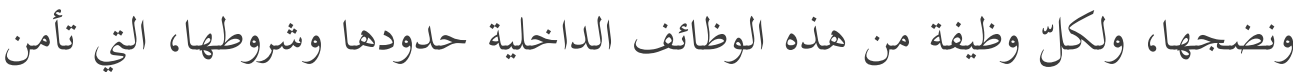

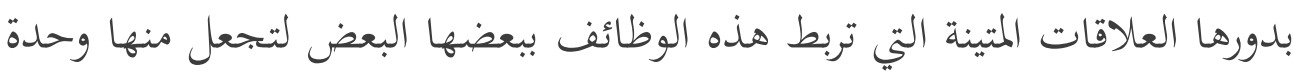

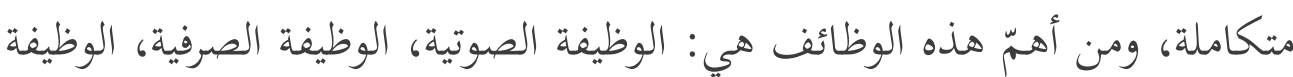

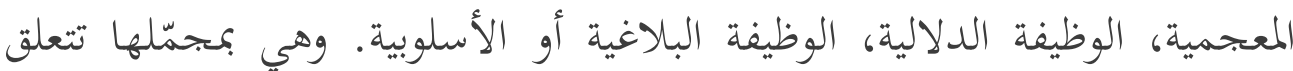

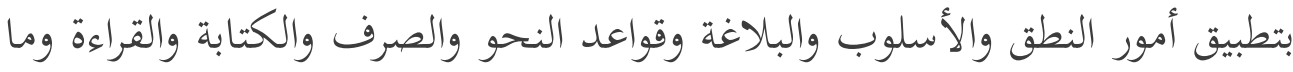

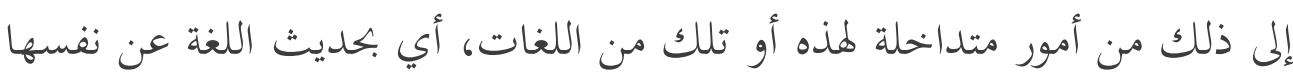
أو الوصف اللغوي للغة ذاتما ولعلاقاتها الداخلية.

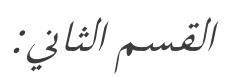

والمقصود هنا الجانب الذاتي، وهو ما يتعلّق باللغة كوغها منظومة متكاملة للتفاهم والتداول والتواصل بين البشر، ويشمل هذا الجحانب الوظائف الإجتماعية

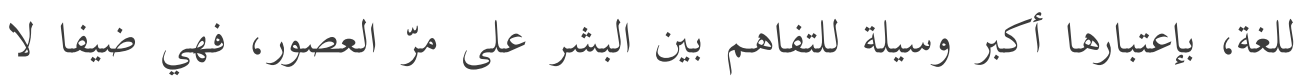

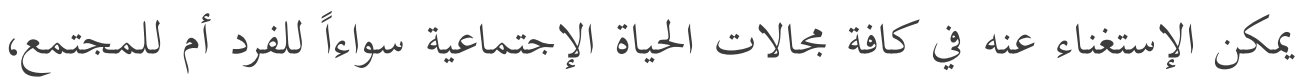

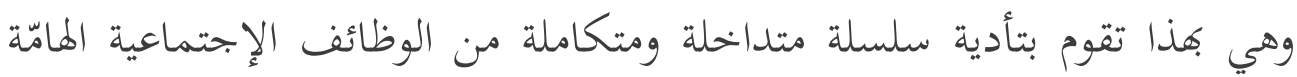

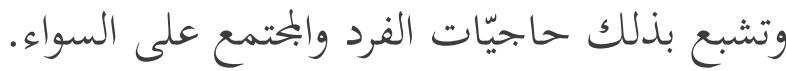

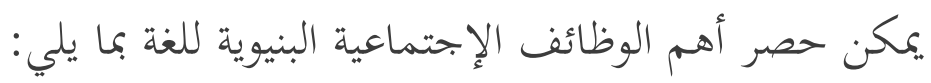

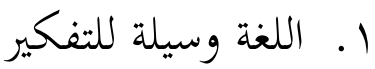

إدا قدم السؤال هل الإنسان يفكر باللغة؟ فلا يوجد أتفاق كامل في مذان

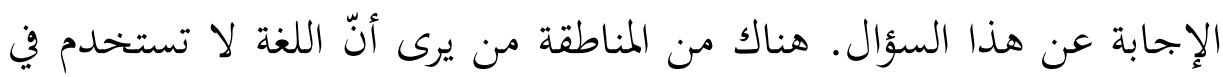

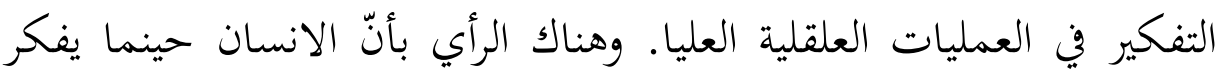

\footnotetext{
معمد شطب، مركز النور للسراسات، و
} 
فهو يستخدم الألفاظ والجمل والتراكيب اللغوية التي تستخدمها في كلامه

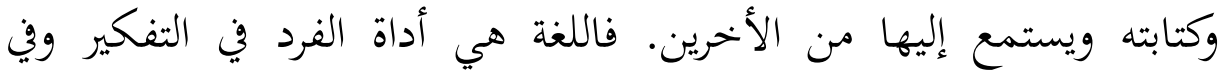
الوصول إلى العمليات العقلية والمدركات الكلية، وبين اللغة كأداة للقيام بهذه التهاه

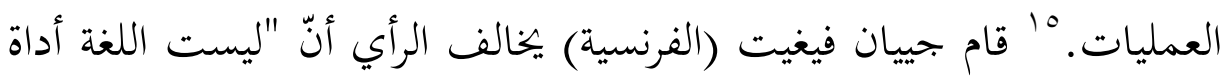

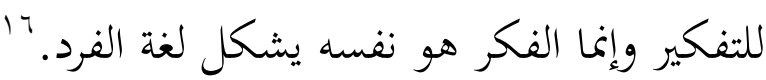

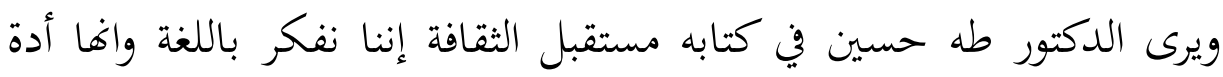
التفكير إذا يقول: نحن نشعر بوجودنا وبحاجتنا المختلفة وعواظفنا المتباينة

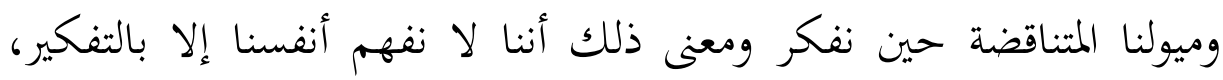

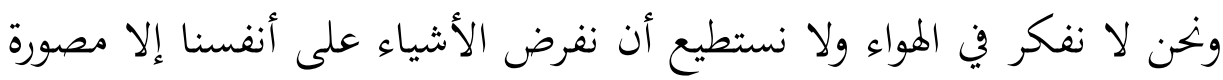

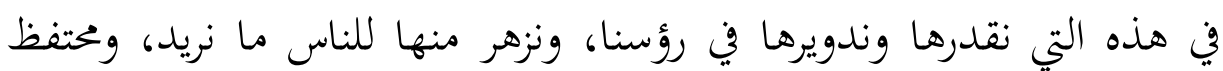

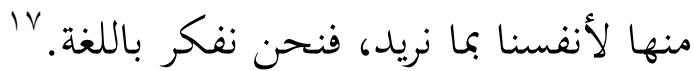

$$
\text { r. تع اللغة وسيلة للتعبير }
$$

هو القالب الذي يصب فيه الإنسان أفكاره بلغة سليمة، وتصوير

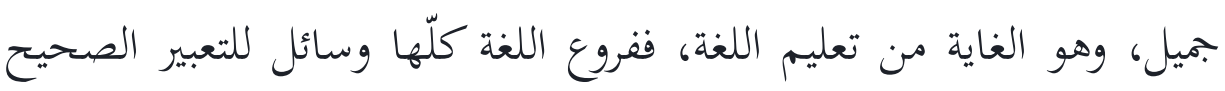

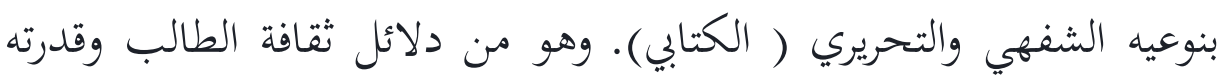

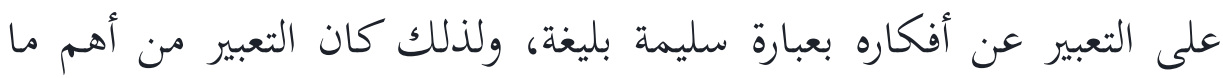

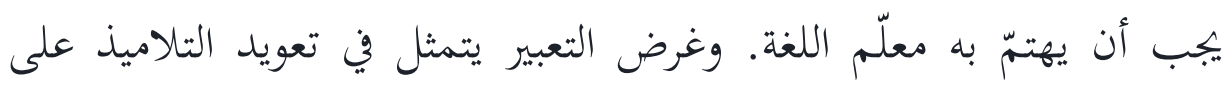
حسن التفكير وجودته، ولتعبير ركنان أساسيان: معنوي، ولفظي، أنسي، أما المعنوي

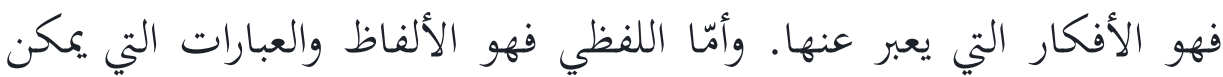

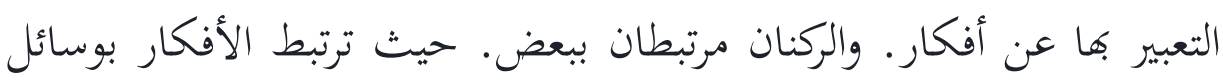

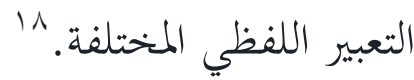

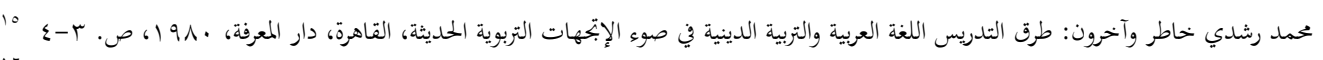

${ }^{17}$ Chaer, Abdul. Y.. . P, Psikolinguistik, Kajian Teoritik. Jakarta, Rineka Cipta.

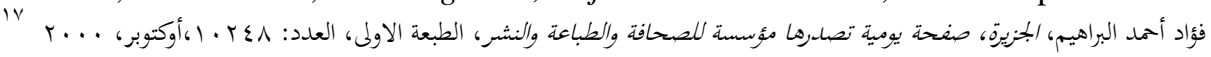

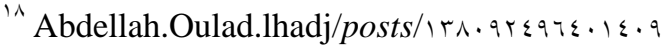


r. - م. اللغة وسيلة للاتصال

توجد الاتصالات حولنا في كلّ الأرجاء. ويستخدم الإنسان اللغة في كلّ

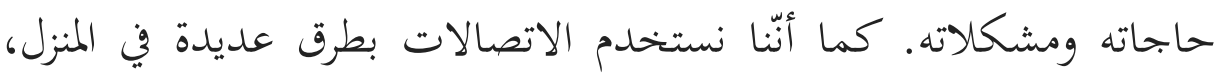

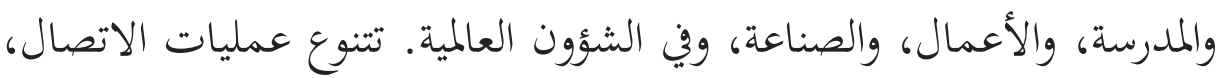

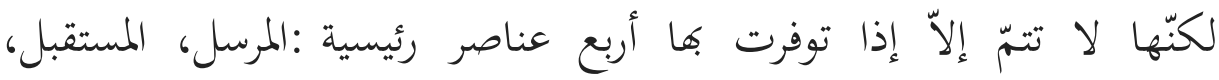
الرسالة، الوسيلة.

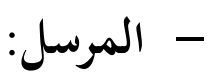

يتمثل بالمسوق أو بحموعة الباعة أو الشركة او أية بحموعة أخرى تكون هادفة إلى إلى

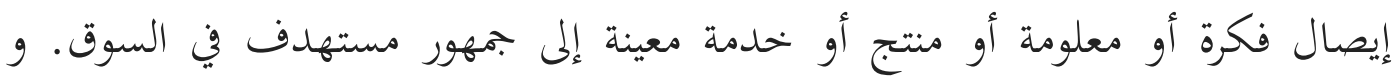

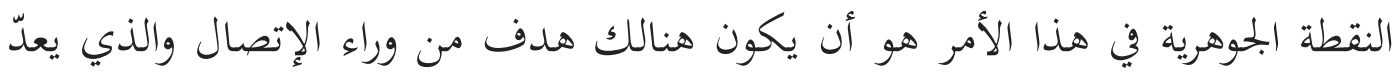

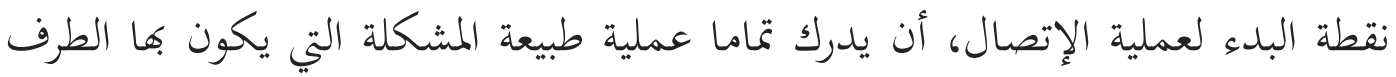

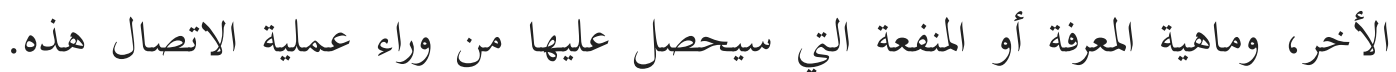

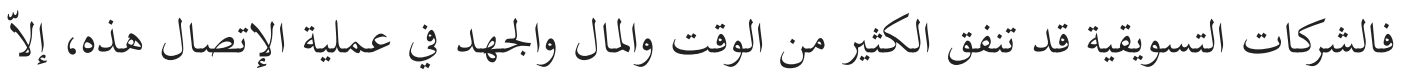

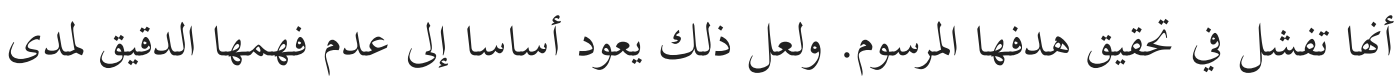

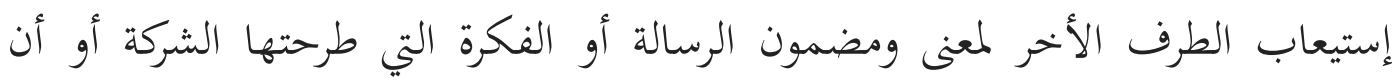

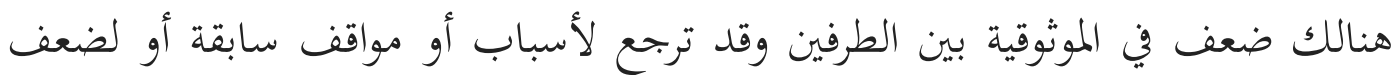

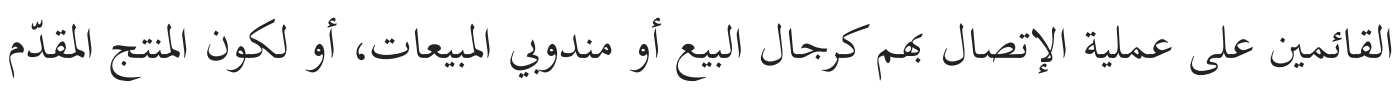

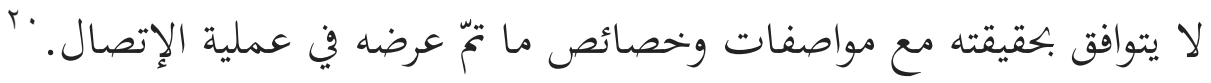

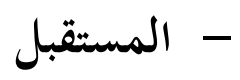

المستقبل أو المتلقّي هو الجمهور الذي يتلقّى الرسالة الإتصالية أو الإعلامية ويتأثر بها

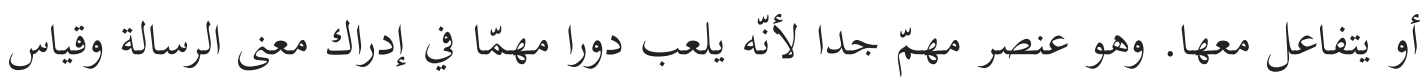
درجة تأثيره في عقلية ذلك الجمهور .

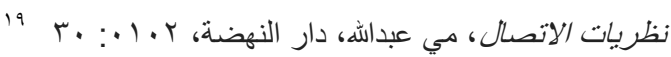

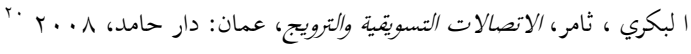




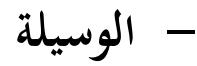

الوسيلة هي الأداة أو القناة التي باستخدامها يتمّ نقل الرسالة من المرسل إلى في

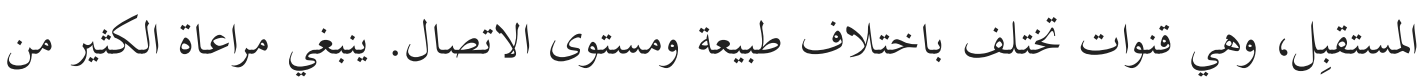

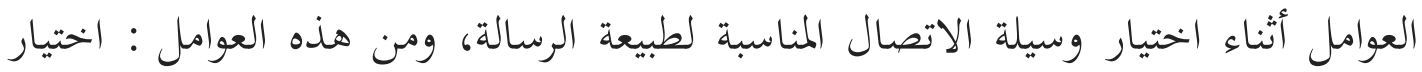

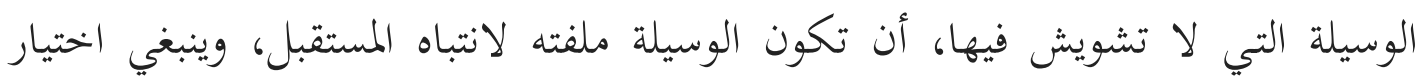

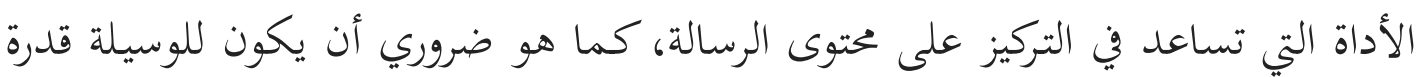

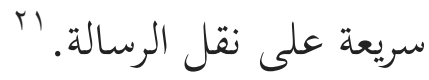

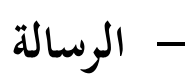

هي جوهر عملية الاتصال لأنما تمثل المضمون أو المختوى لعملية الاتصال التسويقي

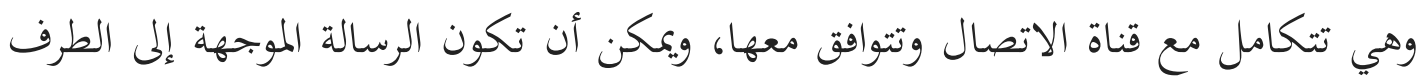

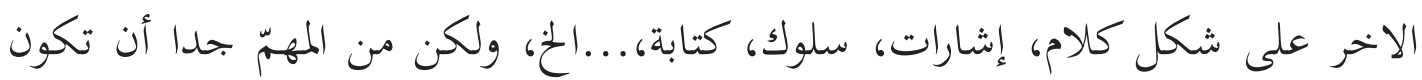

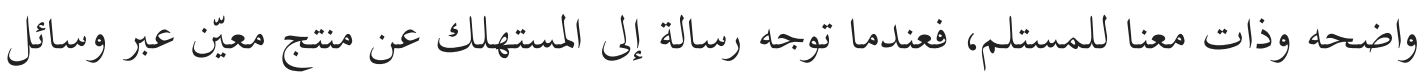

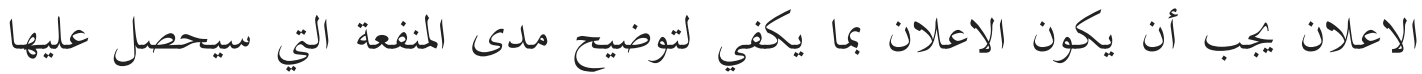

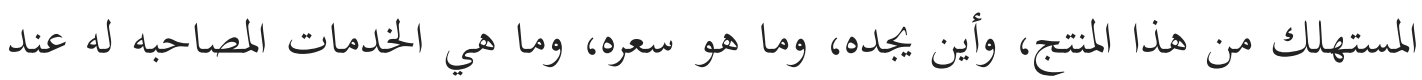

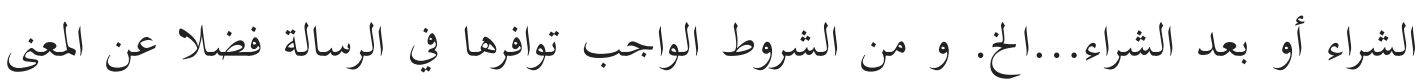

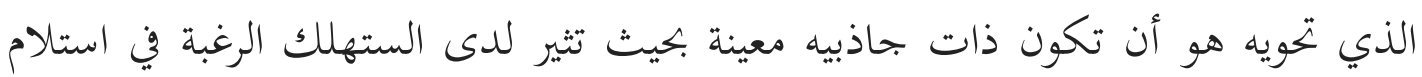

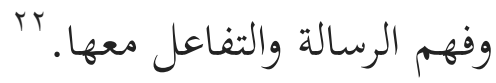

ـ ـ اللغة وسيلة لحفط التراث الثقافي

يقول أحمد مدكور أنّ اللغة عموما تمكن الإنسان من الحفاظ على ثقافته

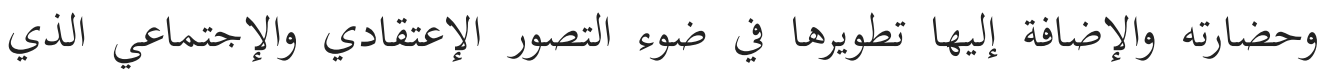

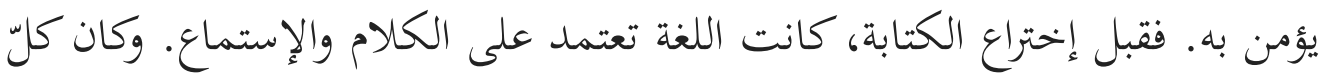

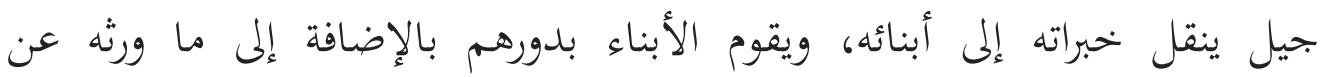

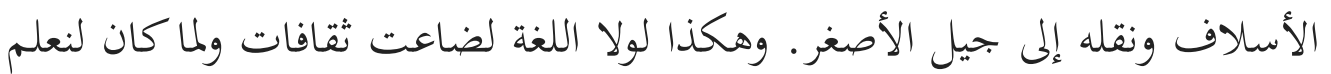

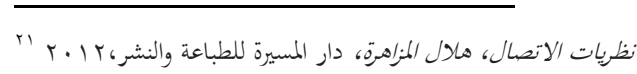
البكري، المراجع السابق.
} 
عنها شيئا الآن. فلمّا إخترعت الكتابة بدأ عصر التسجيل لتراث الأمم وثقافاتما.

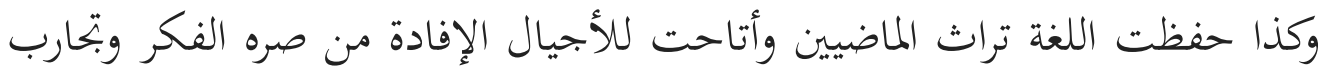

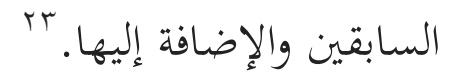

$$
\text { هـ اللغة وسيلة للتعليم والتعلم }
$$

مماذنر في السابق أن اللغة هي وسيلة الفرد في التفكير. الفرد يستخدم الألفاظ

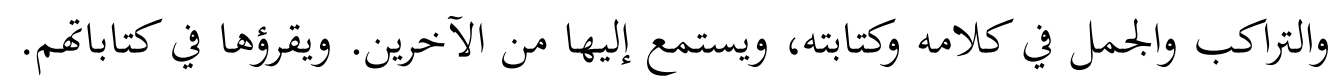

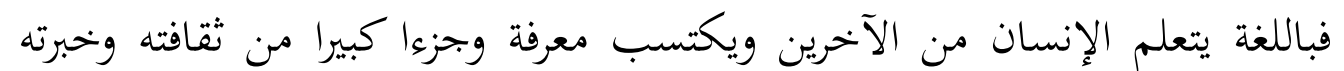

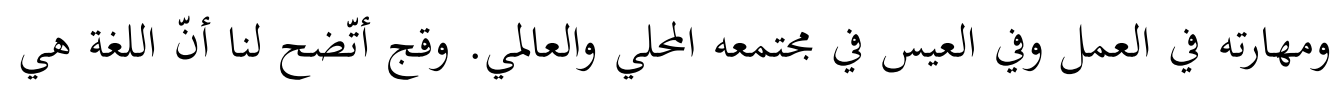

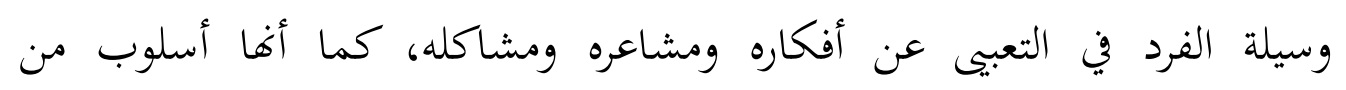

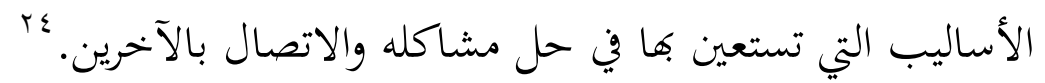

\section{الخحلاصة}

نضيف عى كل ما سبق، نعرف أن اللغة العربية من أهمّ النظم الحضارية. وهي من

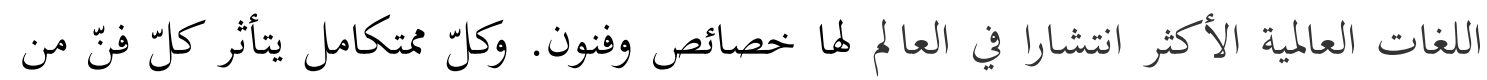

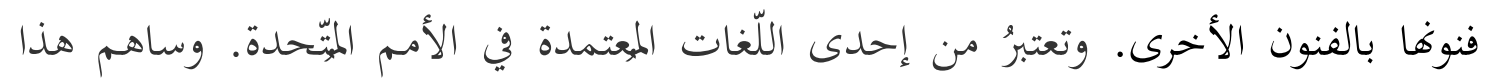

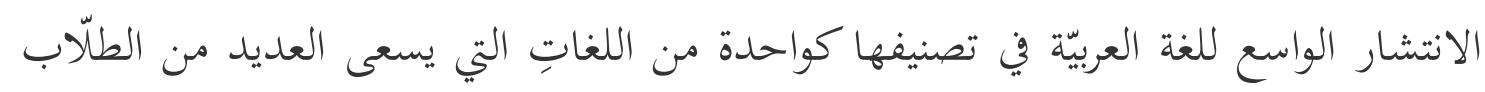

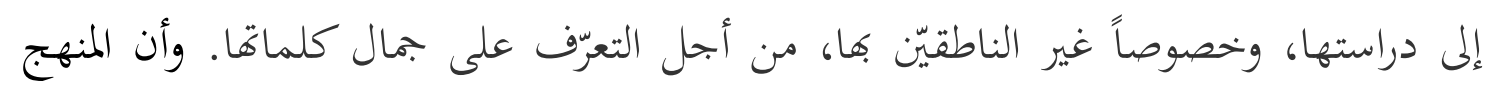

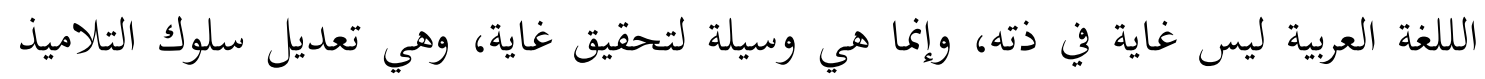

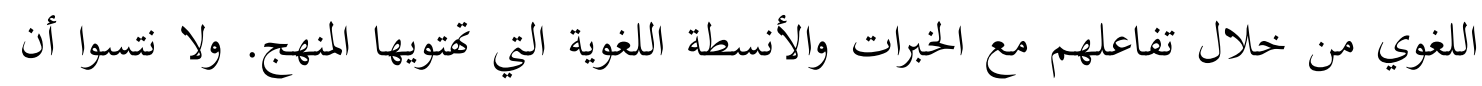
مفهوم اللغة العربية، خصائصها ووطائف تكاملها خحلال عملية التعليم والتعلّم وكثرة الممارسة.

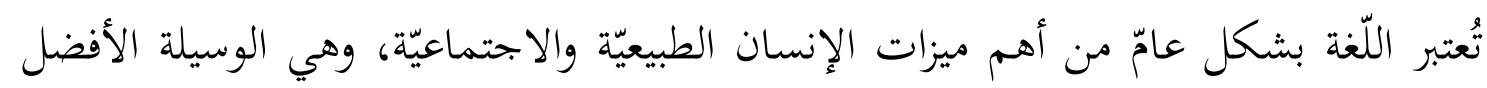

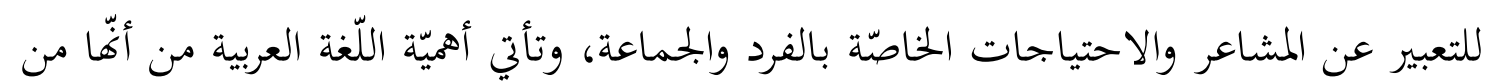

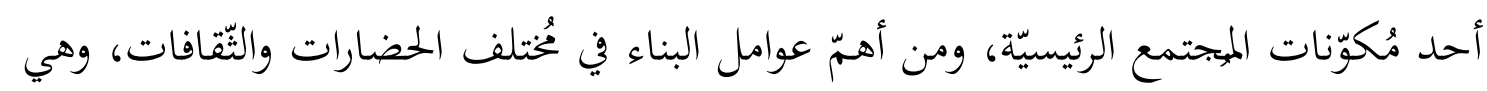

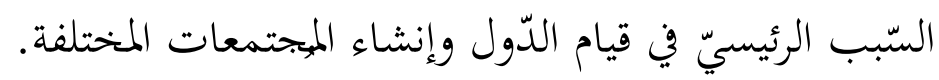

\footnotetext{
علي أحمد مدكور، المراجع السابق، بrr"

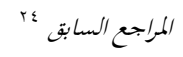




\section{المراجع}

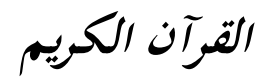

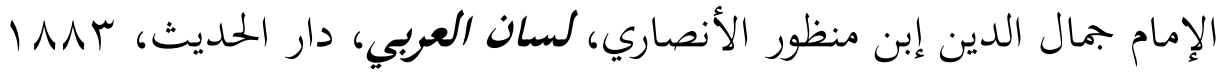

$$
\begin{aligned}
& \text { أحمد مختار، علم الدلالة، علم الكتاب، القاهرة، ب99 } \\
& \text { ثامر البكري، الاتصالات التسويقية والتوويج، عمان: دار حامد، ^ . . † } \\
& \text { إبراهيم السمرائي، تطوير اللغوي التاريخي، بيروت، دار الاندلس، } 919 \text { |م } \\
& \text { علي أحمد مدكور، تلدريس فنون اللغة العربية، دار الشواف، } 999 \text { | }
\end{aligned}
$$

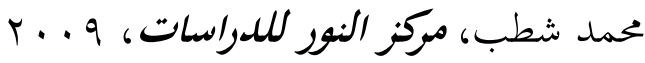

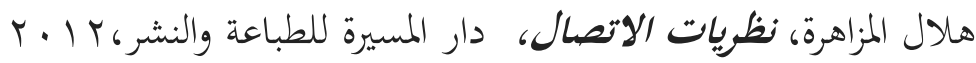

Abduh Rajihi, Fiqh al- Lughah fi al-Kutub al-Arabiyah, (Beirut : Dar al- Nahdah al Arabiyah, 19v9)

Abdul Chaer, Psikolinguistik, Kajian Teoritik. (Jakarta, Rineka Cipta, r..r)

Abu Fath 'Usman Ibn Jinni, al-Khasaish, ( Kairo : al-Mathba'ah al- Hilal, 191\%)

Abu Mansur al-Tsa'alibi, Fiqh Lughah wa Sirr al-Arabiyah, (Beirut : Syirkah Dar alArqam, 1999)

Amil Badi' Ya'kub, Fiqh al-Lughah al-Arabiyah Wa Khasaisuha, (Beirut : Dar alTsaqafah al-Islamiyah, $19 \wedge r$ )

Fromkin, V. \& Roman, R., An Introduction to Language, (New York, Holt, and

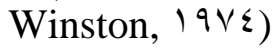

Ibn Manzhur, Lisan, al-Arab,(Beirut : Dar al-Shadr, t.th, ), cet I, Juz Ir

Mahmud Fahmi Hijazi, Ilmu al-Lughah al-Arabiyah : Madkhal Tarikhi Muqoran fi Dhaw al- Turast wa al-lughat al-Samiyah, (Kairo : Dar Gharib li al-Thiba'I wa alNaysr wa al-Tawzi, $\mathrm{tt}$ )

Muhammad Husain Ali Yasin,al-Dirasat al-Lughawiyah 'Inda al-arab Ila Nihayah alQarn al-Tsalis, (Beirut: Mansyurat Dar-Maktabah al-Hayat, 19^•)

Tammam Hassan, al-Ushul : Dirasah Epistimulijiyah li al-Fikr al-Lughawi 'Inda alArab,( Kairo : al-Hai'at al-Mishriyyah al-Ammah li al-Kitab, 19^r)

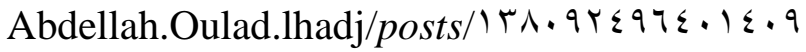

